Calsbeek, H., Rijken, M., Bekkers, M.J.T.M., Kerssens, J.J., Dekker, J., Bergen Henegouwen, G.P. van Social position of adolescents with chronic digestive disorders.

European Journal of Gastroenterology \& Hepatology: 14, 2002, nr. 5, p. 543-549

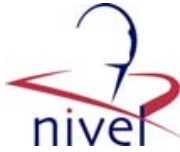

\begin{tabular}{l|l}
$\begin{array}{l}\text { Postprint Version } \\
\text { Journal website }\end{array}$ & 1.0 \\
\hline $\begin{array}{l}\text { Pubmed link } \\
\text { http://meta.wkhealth.com }\end{array}$ & $\begin{array}{l}\text { http://www.ncbi.nlm.nih.gov/entrez/query.fcgi? cmd=Retrieve\&db=pubmed\&dop } \\
\mathrm{t}=\text { Abstract\&list_uids=11984153\&query_hl=16\&itool=pubmed_docsum }\end{array}$ \\
\hline DOI &
\end{tabular}

\title{
Social position of adolescents with chronic digestive disorders
}

\author{
Hiske CALSBEeK ${ }^{\mathrm{A}}$, MieKe RIJKEN ${ }^{\mathrm{A}}$, MARC J.T.M. BeKKERS ${ }^{\mathrm{B}}$, JAN J. KeRSSENS ${ }^{\mathrm{A}}$, JOOST DeKKER ${ }^{\mathrm{A}}$, \\ GERARD P. VAN BERGE HENEGOUWEN ${ }^{\mathrm{C}}$ AND PARTICIPATING CENTRES*
}

${ }^{\text {a }}$ Netherlands Institute of Health Services Research (Nivel), Utrecht,

${ }^{\mathrm{b}}$ PON Institute for Social Research and Development, Tilburg, and

c University Medical Centre Utrecht, Department of Gastroenterology, Utrecht, the Netherlands

* University Medical Centre St Radboud: Dr W. Hopman, Prof. Dr J.B.M.J. Jansen, Dr R.S.V.M. Severijnen and Dr J.J.M. Tolboom; Erasmus Medical Centre Rotterdam/Dijkzigt/Sophia Children's Hospital: Dr J.H.L.J. Bergmeijer, Dr H.R. van Buuren, Dr J. Dees, Dr R. Gerth van Wijk, Dr H. De Groot and Dr M. Sinaasappel; University Medical Centre Utrecht/Wilhelmina Children's Hospital: Prof. Dr C.A.F.M. Bruijnzeel-Koomen, Dr J. van Hattum, Dr R.H.J. Houwen, Dr A.C. Knulst, Dr B. Oldenburg and Dr G. Sinnema; Amsterdam Medical Centre/ Emma Children's Hospital: Dr M.P.R. Cooreman, Dr H.H.F. Derkx, Prof. Dr S.J.H. van Deventer, Dr H.J. Loonen and Dr E.A.J. Rauws; Academical Hospital Groningen: Dr Ch.M.A. Bijleveld, Prof. Dr P.L.M. Jansen and Prof. Dr J.G.R. de Monchy; Dutch Coeliac Disease Association: K. van de Groep and G. Schalekamp; IBD study centre Maastricht: Dr M. Hesselink-van de Kruijs and Dr M.G.V.M. Russel; Leiden University Medical Centre: Dr M. Mearin Manrique; Rijnstate Hospital: Dr C.J.J. Mulder and J. Verhage; Zuider Hospital: Dr R.A.S. Phaff; Juliana Children's Hospital: Dr C.F.M. Gijsbers; and Bosch Medical Centre: Dr Th.J.M. van Ditshuijsen.

Correspondence to Hiske Calsbeek, Nivel, PO Box 1568, 3500 BN Utrecht, the Netherlands Fax: +31 302729 729; e-mail: h.calsbeek@nivel.nl

Objective To investigate the consequences of having a chronic digestive disorder on the social position of adolescents.

Methods Five diagnostic groups, including inflammatory bowel disease (IBD), chronic liver diseases, congenital digestive disorders, coeliac disease and food allergy (total n 758, ages 12-25 years), were each compared with a population-based control group in a multicentre study using a cross-sectional design. Social position was assessed by a mailed questionnaire measuring 24 aspects, categorized as education, leisure activities, friendship, labour participation, financial situation, partnership and sexuality.

Results Eight aspects of social position were found to be affected negatively by one or more chronic digestive diseases: absence from school due to illness, going out, having a paid job, needing re-education in order to get a job, getting benefits as main income source, encountering bottlenecks in establishing financial commitments, having selfconfidence in making a pass at someone, and restrictions in making love. Adolescents with chronic liver disease and IBD were found to experience more restrictions in social position. Adolescents with food allergy and congenital digestive disorders appear to experience some restrictions, but to a lesser degree, and adolescents with coeliac disease do not appear to have any problems regarding social position compared with controls.

Conclusion The social position of adolescents is affected negatively by having a chronic digestive disease, in particular chronic liver disease and IBD. Negative consequences 
Calsbeek, H., Rijken, M., Bekkers, M.J.T.M., Kerssens, J.J., Dekker, J., Bergen Henegouwen, G.P. van Social position of adolescents with chronic digestive disorders.

European Journal of Gastroenterology \& Hepatology: 14, 2002, nr. 5, p. 543-549

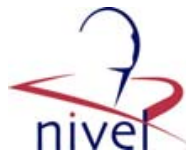

occur in education, leisure activities, labour participation, financial situation, partnership and sexuality.

\section{INTRODUCTION}

Chronic digestive disorders are accompanied by complaints and circumstances, such as pain, fatigue, growth arrears, diet commitments, decreased physical condition, flatulence and incontinence, that can have negative social consequences. These negative consequences are especially important in adolescence, as in this period choices are being made that are directive for future life.

Scientific knowledge of the social position of patients with chronic digestive disorders is limited and mostly involves adult patients in non-controlled designs [1-4]. In general, these studies show that difficulties are met in particular in the domain of labour participation, financial matters, social contacts and relationships. Adult patients with chronic digestive disorders seem to emphasize social restrictions more than physical restrictions.

Unlike previous studies, we wished to investigate the social position of adolescents between the ages of 12 and 25 years suffering from inflammatory bowel disease (IBD), chronic liver diseases, congenital digestive disorders, coeliac disease or food allergy in comparison with a control group. Exact data indicating the prevalence of these diseases in the Netherlands do not exist $[5,6]$, but the estimated prevalence in the age group 15-24 years of IBD is $0.06 \%$ [7], chronic liver disease $0.9 \%$ [8], congenital digestive disorders $0.01-0.1 \%$ [1,7-9], coeliac disease $0.07 \%$ [10], and food allergy $0.3-$ $7.5 \%$ in children and $2 \%$ in adults [11].

The aim of this study was to determine whether having a chronic digestive disorder has a negative influence on the social position of adolescents in general, and to identify the specific aspects of social position affected negatively by having various chronic digestive disorders.

\section{METHODS}

\section{Subjects}

Five diagnostic groups, including IBD, chronic liver diseases, congenital digestive disorders, coeliac disease and food allergy, were each compared with a population- based control group in a multicentre study. Patients were recruited via 25 medical specialists in 11 academic and specialized hospitals using the following criteria: being diagnosed within one of five diagnostic categories stated by a certified medical specialist, illness duration of at least 6 months, age 12-25 years, being noninstitutionalized, being aware of diagnosis, not being terminally ill, being mentally capable to participate, and mastering the Dutch language sufficiently. In classifying patients, the translation of the International Classification of Diseases, 10th revision (ICD-10) [12] was used. Extra patients with coeliac disease were recruited through a patient organization using the same criteria (diagnosis had to be confirmed by at least one small-bowel biopsy). There was no selection on illness activity or severity of complaints and disability.

In the Netherlands, (almost) every inhabitant is registered with a general practitioner, so controls were recruited randomly from the patient files of 173 general practitioners of participating patients. In recruiting controls, the same criteria were used as for the recruitment of patients (except for being diagnosed within one of five of the diagnostic categories). General practitioners were provided with a random set of three different letters of the alphabet on the basis of which they were requested to select three controls with surnames starting with the indicated letters and fitting the specified criteria.

In order to realize an adequate response, subjects were reminded about the study up to three times. The study was approved by all participating hospitals' ethical committees. All subjects gave written informed consent.

\section{Measurement}

Data were collected by a survey among the subjects.

\section{Background variables}

Next to gender and age, socioeconomic status and puberty were measured as background variables. Socioeconomic status was indicated by the highest education of one of the parents or carers assessed 
Calsbeek, H., Rijken, M., Bekkers, M.J.T.M., Kerssens, J.J., Dekker, J., Bergen Henegouwen, G.P. van Social position of adolescents with chronic digestive disorders.

European Journal of Gastroenterology \& Hepatology: 14, 2002, nr. 5, p. 543-549

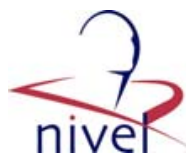

on a seven-point scale from $1=$ no or only primary education to $7=$ completed university training. Puberty was assessed by the following physical characteristics: having had the first menstruation in the case of female subjects, and the presence of a heavy voice in combination with axillary hair in male subjects.

\section{Social position}

Social position was assessed by 24 aspects relating to education, leisure activities, friendship, labour participation, financial situation, partnership and sexuality. Education was assessed by five aspects: (1) absence due to illness (number of whole weeks during total school time), (2) failing classes (dichotomized: at least once v. never), (3) final educational level, (4) educational level during school period (seven-point scale), and (5) having a sideline job (having/not having a paid job for $<12 \mathrm{~h} /$ week).

Leisure activities were assessed by two scales derived from the Netherlands Health Interview Survey [13]: (1) going out (3 items, Cronbach's alpha 0.63) and (2) undertaking cultural activities (four items, Cronbach's alpha 0.63 ). The scale 'going out' consisted of the following items: going to the cinema, going to a disco or house party, and visiting a pub; the scale 'undertaking cultural activities' was assessed by the following items: visiting a library, play or concert, visiting a museum, and reading books. All items were scored on a four-point scale. In order to facilitate interpretation, the scale scores were transposed to the same format (1-4).

Friendship was assessed by one scale derived from the national survey Youth and Sex [14] consisting of two items: having friends and undertaking activities with friends (Cronbach's alpha 0.64). As both items were scored on a five-point scale, the scale score was transposed to the same format to facilitate interpretation.

Labour participation was assessed by six aspects: (1) having a paid job (having/not having a paid job of at least $12 \mathrm{~h} /$ week), (2) number of months to get the first job, (3) needing re-education in order to get a job (yes/ no), (4) number of working hours a week, (5) having a permanent job (yes/no), and (6) having a job of at least educational level (yes/no).

The financial situation was assessed by two aspects: (1) getting benefits as main income source (yes/no) and (2) meeting difficulties in establishing financial commitments (dichotomized: at least once v. never), such as in taking out an insurance or mortgage or another kind of loan.

Partnership was assessed by three aspects: (1) having a partner (yes/no), to be completed only by respondents aged $\geq 18$ years in order to be comparative with national statistics [15]; (2) making a pass at someone, derived from the national survey Youth and Sex [14] (dichotomized: having made a pass at someone at least once v. never); and (3) self-confidence in making a pass at someone, derived from the same questionnaire [14], consisting of a six-item scale (Cronbach's alpha 0.70), in which each item was scored on a four-point scale.

Sexuality was assessed by four aspects, all derived from the national survey Youth and Sex [14]: (1) experience with sex (dichotomized: having made love to someone at least once v. never), to be completed only by respondents being financially self-supporting so that younger respondents were prevented from filling in this question); (2) experience with sex compared with friends, scored on a five-point scale; (3) contentment with sex life, scored on a ten-point scale; and (4) feeling restricted in making love (dichotomized: feeling restricted regularly v. never or sometimes).

\section{Statistical analysis}

To describe the sample, analysis of variance (ANOVA) was applied using Scheffé's (homogeneous groups) or Tamhane's T2 (non-homogeneous groups) procedure for comparing means and the chisquared test for comparing percentages (two-tailed significance level of 0.01 ).

In order to test differences with regard to aspects of social position between diagnostic groups and the control group, ANOVA (continuous variables) or the logistic regression procedure (dichotomous variables) was performed (one-tailed significance level of 0.01). Additionally, after the overall test had shown significance, the simple contrast method was used to compare each diagnostic group with the control group (reference category). The simple contrast method allows for comparing each category of the predictor variable (except the reference category) with the reference category in one analysis. In these procedures, age, gender and socioeconomic status were added as covariates (in logistic regression procedure in a separate block) to control for their effects. These three background variables 
Calsbeek, H., Rijken, M., Bekkers, M.J.T.M., Kerssens, J.J., Dekker, J., Bergen Henegouwen, G.P. van Social position of adolescents with chronic digestive disorders.

European Journal of Gastroenterology \& Hepatology: 14, 2002, nr. 5, p. 543-549

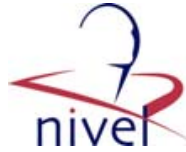

appeared to differ significantly between groups (see Description of the sample below), while being associated with most of the outcome measures.

\section{RESULTS}

\section{Description of the sample}

The sample consisted of 758 patients suffering from IBD $(n=305)$, or a chronic liver disease $(n=$ $94)$, or a congenital digestive disorder $(n=137)$, or coeliac disease $(n=124)$ or food allergy $(n=98)$. The mean response was $57.1 \%$, varying from $48.7 \%$ in adolescents with chronic liver diseases to $67.2 \%$ in adolescents with IBD. The sample also included 306 controls with a response rate of $54.7 \%$.

Table 1 summarizes the characteristics of each diagnostic and control group. The mean age varied from 17.5 years to 20.0 years in the different groups, the IBD group being significantly older than the control group. Among the diagnostic groups, no significant differences were found. The percentage of female subjects varied from $47 \%$ to $69 \%$. No significant differences were found between diagnostic groups and the control group; differences were only found among three diagnostic groups. The mean score on socioeconomic status varied from 3.9 to 4.8. None of the diagnostic groups differed significantly from the control group; differences existed only among diagnostic groups. The percentage of participants that had not reached puberty varied from $9 \%$ to $19 \%$, showing no significant differences between the diagnostic groups and control group or between the diagnostic groups.

\section{[ TABLE 1 ]}

\section{Representativeness of the control group}

In order to verify the representativeness of the control group, three aspects were compared with available national statistics of the Dutch population between the ages of 12 and 25 years. National statistics on educational level [15] indicate that $4.8 \%$ had no education or primary school, $74.7 \%$ had secondary education and $20.5 \%$ had higher education. In our control group, these figures are, respectively, $0.9 \%, 72.7 \%$ and $26.9 \%$. With respect to failing classes, $32.5 \%$ of the controls who failed at least once (Table 2) seems a high percentage. However, available national statistics on this aspect [15] indicate that in three different grades of secondary schools, $23 \%, 42 \%$ and $31 \%$ fail classes. These percentages include pupils and students who fail a second time, but they do not cover the total school period as in our study. A third aspect that was suitable for comparison with national statistics involves partnership. National data on relationships [13] point out that $63 \%$ of the female population between the ages of 18 and 25 years report having a partner; in our control group, $61 \%$ of the females in the same age group reported having a partner. On the basis of these data, the control group was considered representative for the general population.

\section{[ TABLE 2 ]}

\section{Social position}

Tables 2 and 3 display the mean scores and percentages on the outcome measures for each diagnostic group and the control group.

\section{[ TABLE 3 ]}

\section{Education}

One of the five aspects of education, number of weeks absent due to illness, was found to be affected by three chronic digestive diseases: adolescents with IBD, chronic liver disease and food allergy show a significantly higher number of weeks absence during their school period compared with controls (Table 2). 


\section{Leisure activities}

One of two aspects, going out, was found to be affected by two chronic digestive diseases: adolescents with IBD and chronic liver disease report going out significantly less often in comparison with controls (Table 2). This means that they go less often to the cinema, discos or house parties, and pubs.

\section{Friendship}

The results in Table 2 show that none of the diagnostic groups differed significantly from the control group on this aspect.

\section{Labour participation}

Two out of six aspects of labour participation were found to be affected by one or more chronic digestive diseases: having a paid job and needing re-education (Table 3). Adolescents with IBD and chronic liver disease appear to have a paid job significantly less often than controls. Furthermore, adolescents with chronic liver disease report significantly more often the need for re-education in order to get a job compared with controls.

\section{Financial situation}

Both aspects of financial situation were found to be affected by having a chronic digestive disorder (Table 3). First, compared with controls, adolescents with IBD appear to be significantly more dependent on benefits as a main income source. Second, adolescents with chronic liver disease meet difficulties significantly more often in establishing financial commitments, such as being refused insurance, having to pay a higher insurance premium, or being refused a mortgage or other kind of loan.

\section{Partnership}

One out of the three partnership aspects, self-confidence in making a pass at someone, was found to be affected by two chronic digestive diseases: chronic liver disease and food allergy. Both aspects were assessed in respondents not having a partner. Table 3 shows that adolescents with chronic liver disease and food allergy have significantly less self-confidence in making a pass at someone.

\section{Sexual functioning}

One out of the four sexual functioning aspects, regularly feeling restricted in making love, appeared to be affected by having a chronic digestive disease: compared with controls, significantly more adolescents with congenital digestive disorders feel restrictions in making love, i.e. feeling ashamed (Table 3).

\section{DISCUSSION}

In this study, five diagnostic groups were each compared with a population-based control group with respect to social position. Results indicate that several aspects of social position of adolescents are affected negatively by having a chronic liver disease or IBD. These aspects include a higher absence from school due to illness, going out less often, getting a paid job less often, needing re-education more often in order to get a job, being dependent more often on benefits as a main income source, meeting difficulties in establishing financial commitments more often, and having less selfconfidence in making a pass at someone. Thus, suffering from a chronic liver disease or IBD can have a serious impact on the social position of adolescents in daily life, now and in the future.

Chronic liver diseases can be considered as disorders that are accompanied by physical barriers, such as pain, fatigue and an unstable physical condition. In order to finish education successfully, or to find and keep a suitable job, these patients have to put in extra effort. Having low energy levels and not being able to drink alcohol are possible explanations for not going out as often as adolescents without these disorders. Being a carrier of a sexual transmittable disease, such as viral hepatitis, makes it even more difficult to mix with other adolescents. 


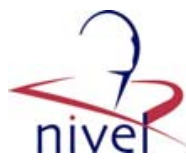

IBDs are accompanied by several physical barriers, so that extra effort is needed to live a life like those of healthy peers. In a study in adult Crohn's disease patients [2], it was stated that more effort was needed to reach the same educational level as the general population. Drossman et al. [3] also concluded that IBD patients were mostly impaired in work, recreation and the psychosocial area of social interaction, even with only minor physical dysfunction. In a recent study in adult patients with IBD [16], it was found that all dimensions of the health-related quality of life (HRQOL), including the social dimension, were impaired during relapses of the disease.

The social position of adolescents being diagnosed with food allergy appears to be affected, but to a lesser degree. In the domain of education, it appears that adolescents with food allergy report a higher absence from school due to illness compared with peers. Furthermore, results indicate that adolescents with food allergy have less self-confidence in making a pass at someone. Food allergy can be considered a disease that is controllable very well by following a diet in which the product causing the allergic reaction is left out. In general, when the prescribed diet is followed strictly, it is possible to live a normal life. However, dietary nonadherence can cause immediate allergic reactions, varying from very mild symptoms caused by a broad scale of food products to very serious symptoms following the intake of only one food product.

Being diagnosed with a congenital disorder appears to have few consequences on the position of adolescents compared with peers. Findings from a study on functional health after neonatal surgery [17] suggest that the impact of a congenital digestive disorder on the social position can largely be reduced by surgery. In the present study, one aspect in the domain of sexuality appeared to be affected: adolescents with a congenital disorder feel more restrictions in making love than adolescents without chronic digestive disorders. In the other domains of social position, no effects were found. In a study in adult patients with anorectal malformations [1], it was concluded that many patients feel restricted in (building) relationships. No restrictions were found regarding labour participation and leisure activities compared with the general population. Finally, as appears from this study, being diagnosed with coeliac disease does not necessarily have to induce restrictions in the social position of adolescents. In the present study, no aspect appeared to be affected by coeliac disease. Coeliac disease is a disorder that can be controlled well by following a gluten-free diet. When this diet is adhered to, it is possible for patients to live a normal life. When this diet is not followed strictly, it does not have immediate physical consequences. Although the diet requires a lot of creativity in replacing cereal products, it conclusively does not have social consequences, as measured in this study.

In interpreting these results, some points of consideration have to be taken into account. First, although the included five diagnostic groups represent the majority of chronic digestive diseases, not every chronic digestive disease is represented. For example, chronic digestive disorders in cystic fibrosis were excluded because a study [18] on the medical, psychological and social consequences of cystic fibrosis was carried out in the Netherlands in the same period. Second, the fact that many patients were recruited by clinicians in academic centres may have led to selection bias. However, there is no indication that a selection was made of the more seriously ill patients, as the Dutch healthcare system is organized in such a manner that most adolescents, and especially younger children, with chronic disease are treated and controlled in specialized centres. A third point of consideration involves the representativeness of participating controls. In order to verify whether the control group was representative for the Dutch population between the ages of 12 and 25 years, some data were compared with available national statistics. Although not every aspect was compared with national statistics (not every aspect was suitable for comparison), the control group was considered representative for the general population. Another limitation concerns the measurement of puberty. Puberty status was taken into account because of the assumption that chronic disorders can be accompanied with a delayed puberty [5], a factor that could play a role in several aspects of social position. Although not as strong as it could be, we judged puberty status from self-reports on some physical characteristics. Finally, because of the small numbers in the subgroups, small effects could not be shown in this study.

When these considerations are taken into account, it can be concluded that being diagnosed with a chronic liver disease or IBD has consequences for the social position of adolescents. Apart from physical functioning, it is important to recognize this impact in assessing the health status, so that potential restrictions can be identified by clinicians, and adolescents can be supported in the prevention of social restrictions. In order to provide concrete points of application for prevention and 
Calsbeek, H., Rijken, M., Bekkers, M.J.T.M., Kerssens, J.J., Dekker, J., Bergen Henegouwen, G.P. van Social position of adolescents with chronic digestive disorders.

European Journal of Gastroenterology \& Hepatology: 14, 2002, nr. 5, p. 543-549

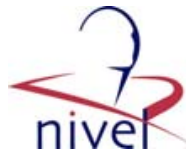

support, further research is needed into how these adolescents cope with their diseases and what other factors, such as illness characteristics and personal and environmental characteristics, play a mediating role in experiencing social restrictions.

\section{ACKNOWLEDGEMENTS}

We thank the following people for their support in this study: N. Feijten, Dr F.M. Mastenbroek, Dr E. Kampman, Dr K. Wittebrood, Prof. Dr C. Festen and Dr M. Sinaasappel.

\section{TABLES}

Table 3 Social position of patients and controls

\begin{tabular}{|c|c|c|c|c|c|c|c|}
\hline & $\begin{array}{l}\text { Inflammatory } \\
\text { bowel disease }\end{array}$ & $\begin{array}{l}\text { Chronic liver } \\
\text { disease }\end{array}$ & $\begin{array}{l}\text { Congenital } \\
\text { digestive } \\
\text { disorders }\end{array}$ & Coeliac disease & Food allergy & Control group & \\
\hline \multicolumn{8}{|l|}{ Labour participation } \\
\hline Having a paid job $(\%)^{1}$ & $68.0^{*}$ & $67.6^{*}$ & 72.0 & 71.9 & 63.4 & 77.5 & $\mathrm{Chi}^{2}(5)=17.62, P=0.002$ \\
\hline $\begin{array}{l}\text { Number of months to get first job } \\
(\text { mean, SD })^{2}\end{array}$ & $2.6(4.9)$ & $4.8(15.0)$ & $2.1(4.5)$ & $1.1(2.6)$ & $1.7(2.4)$ & $2.8(9.6)$ & NS \\
\hline Needing re-education $(\%)^{1}$ & 13.2 & $22.2^{*}$ & 13.9 & 12.5 & 0.0 & 4.4 & Wald $(1)=5.99, P=0.007$ \\
\hline $\begin{array}{l}\text { Number of working hours/week } \\
(\text { mean, SD })^{2}\end{array}$ & $34.3(7.2)$ & $34.2(7.2)$ & $35.2(6.5)$ & $35.4(6.9)$ & $34.0(5.6)$ & $36.1(5.2)$ & NS \\
\hline Having permanent job $(\%)^{2}$ & 78.4 & 76.0 & 72.2 & 82.6 & 69.2 & 82.6 & NS \\
\hline $\begin{array}{l}\text { Having job of at least education level } \\
(\%)^{2}\end{array}$ & 81.7 & 88.5 & 91.4 & 95.7 & 88.5 & 81.1 & NS \\
\hline \multicolumn{8}{|l|}{ Financial situation } \\
\hline $\begin{array}{l}\text { Getting benefits as main income } \\
\text { source }(\%)^{3}\end{array}$ & $13.6^{*}$ & 10.8 & 7.0 & 2.0 & 4.5 & 3.9 & $\mathrm{Chi}^{2}(5)=3.62, P=0.009$ \\
\hline $\begin{array}{l}\text { Bottlenecks in establishing financial } \\
\text { commitments }(\%)^{4}\end{array}$ & 25.6 & $43.5^{*}$ & 25.0 & 22.2 & 11.8 & 15.9 & Wald $(1)=6.65, P=0.005$ \\
\hline \multicolumn{8}{|l|}{ Partnership } \\
\hline Having a partner $(\%)^{5}$ & 49.1 & 42.2 & 40.8 & 56.7 & 55.4 & 53.3 & NS \\
\hline Making a pass at someone $(\%)^{6}$ & 61.2 & 52.0 & 54.8 & 56.0 & 52.6 & 65.0 & NS \\
\hline $\begin{array}{l}\text { Self-confidence in making a pass at } \\
\text { someone, range } 1-4 \text { (mean, SD) }\end{array}$ & $2.2(0.6)$ & $2.1(0.7)^{*}$ & $2.3(0.5)$ & $2.1(0.6)$ & $2.1(0.6)^{*}$ & $2.3(0.5)$ & $\mathrm{F}(5)=2.81, P=0.008$ \\
\hline \multicolumn{8}{|l|}{ Sexuality } \\
\hline Experience with sex $(\%)^{3}$ & 75.8 & 72.7 & 69.5 & 76.5 & 73.9 & 78.0 & NS \\
\hline $\begin{array}{l}\text { Experience compared with friends, } \\
\quad \text { range } 1-5 \text { (mean, SD) }^{8}\end{array}$ & $2.7(0.9)$ & $2.7(1.0)$ & $2.7(0.9)$ & $2.8(0.9)$ & $2.8(1.0)$ & $2.8(0.9)$ & NS \\
\hline $\begin{array}{l}\text { Contentment with sex life, range } \\
1-10(\text { mean, SD })^{9}\end{array}$ & $6.9(2.5)$ & $6.8(2.3)$ & $6.5(2.3)$ & $7.5(2.0)$ & $7.2(2.4)$ & $6.9(2.2)$ & NS \\
\hline $\begin{array}{l}\text { Regularly feeling restricted in making } \\
\text { love }(\%)^{10}\end{array}$ & 13.1 & 10.7 & $18.9^{*}$ & 0.0 & 19.4 & 4.5 & Wald $(1)=5.48, P=0.010$ \\
\hline
\end{tabular}

$* P \leqslant 0.01$ in comparison with control group (after controlling for differences in age, gender and socioeconomic status).

${ }^{1}$ To be completed by respondents who had finished education $(n=234)$.

${ }^{2}$ To be completed by respondents with a paid job ( $\geqslant 12$ working hours/week) $(n=303)$.

${ }^{3}$ To be completed by respondents being financially independent, e.g. paid job, financial study support or benefits $(n=535)$.

${ }^{4}$ To be completed by respondents having made at least one financial commitment $(n=227)$.

${ }^{5}$ To be completed by respondents aged $\geqslant 18$ years $(n=651)$.

${ }^{6}$ To be completed by respondents aged $\geqslant 15$ years not having a partner $(n=498)$.

$7_{1}=$ no self-confidence to $4=$ much self-confidence, to be completed by respondents aged $\geqslant 15$ years not having a partner $(n=498)$.

$81=$ much less experience to $5=$ much more experience, to be completed by all respondents $(n=1064)$.

$9_{1}=$ very discontented to $10=$ very contented, to be completed by respondents who have had experience with $\operatorname{sex}(n=403)$

${ }^{10}$ To be completed by respondents who have had experience with sex $(n=403)$. 
Calsbeek, H., Rijken, M., Bekkers, M.J.T.M., Kerssens, J.J., Dekker, J., Bergen Henegouwen, G.P. van Social position of adolescents with chronic digestive disorders.

European Journal of Gastroenterology \& Hepatology: 14, 2002, nr. 5, p. 543-549
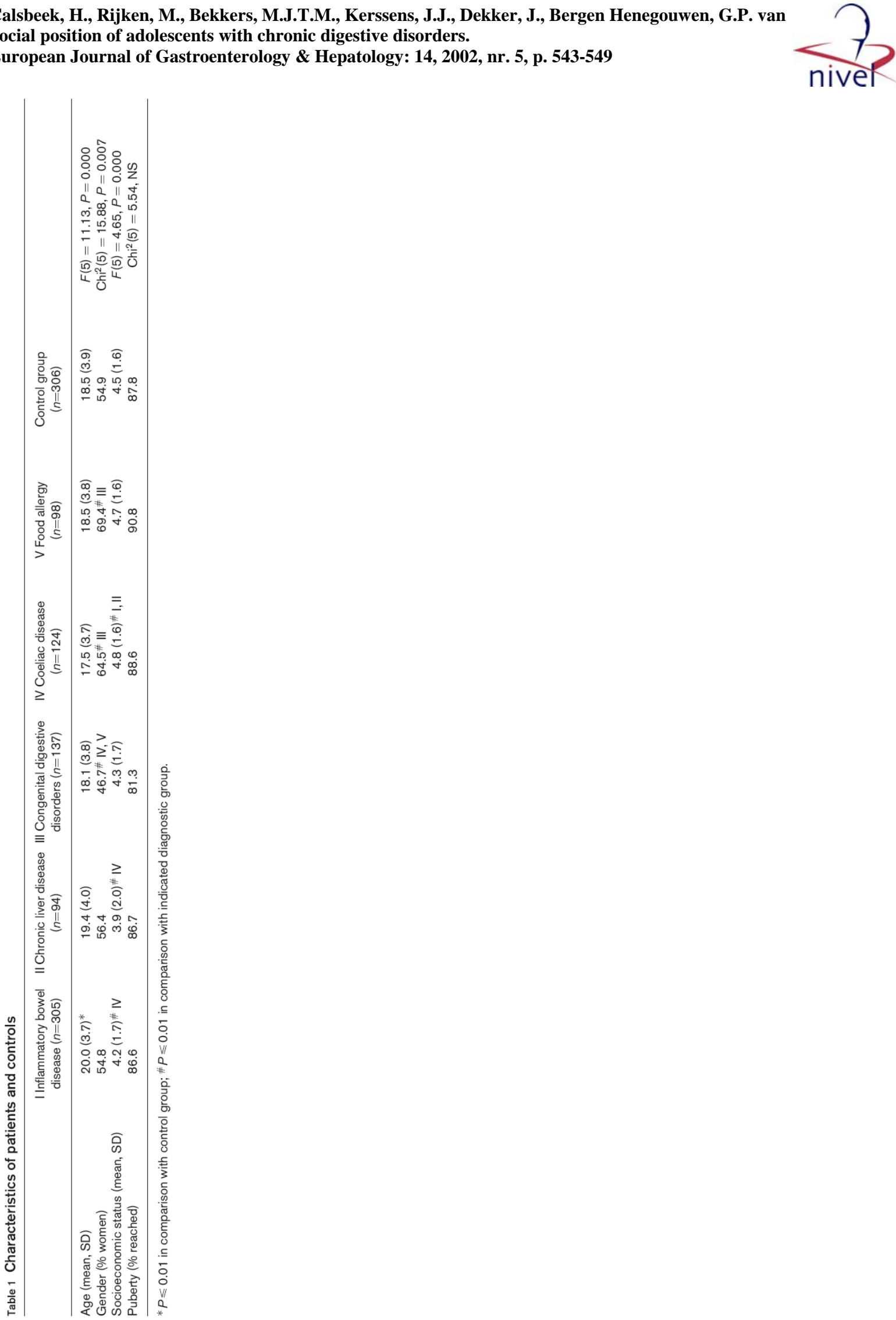
Calsbeek, H., Rijken, M., Bekkers, M.J.T.M., Kerssens, J.J., Dekker, J., Bergen Henegouwen, G.P. van Social position of adolescents with chronic digestive disorders.

European Journal of Gastroenterology \& Hepatology: 14, 2002, nr. 5, p. 543-549

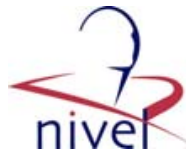

\begin{tabular}{|c|c|c|c|c|c|c|c|}
\hline & $\begin{array}{l}\text { Inflammatory } \\
\text { bowel disease }\end{array}$ & $\begin{array}{l}\text { Chronic liver } \\
\text { disease }\end{array}$ & $\begin{array}{l}\text { Congenital } \\
\text { digestive } \\
\text { disorders }\end{array}$ & Coeliac disease & Food allergy & Control group & \\
\hline \multicolumn{8}{|l|}{ Education } \\
\hline $\begin{array}{l}\text { Number of weeks absence due to } \\
\text { illness (mean, SD) }\end{array}$ & $13.4(21.0)^{*}$ & $7.5(13.8)^{*}$ & $4.7(12.0)$ & $4.4(13.2)$ & $7.5(19.9)^{*}$ & $1.6(6.0)$ & $F(5)=15.82, P=0.000$ \\
\hline Failing classes $(\%)$ & 42.4 & 40.0 & 34.8 & 24.4 & 32.7 & 32.5 & NS \\
\hline $\begin{array}{l}\text { Final educational level, range } 1-7 \\
\quad(\text { mean, SD })^{1}\end{array}$ & $3.6(1.4)$ & $2.9(1.4)$ & $3.4(1.6)$ & $3.9(1.5)$ & $4.1(1.7)$ & $3.9(1.5)$ & $F(5)=2.97, P=0.007$ \\
\hline $\begin{array}{l}\text { Educational level during school } \\
\text { period, range } 1-7 \text { (mean, SD) }{ }^{2}\end{array}$ & $4.7(1.5)$ & $4.6(1.7)$ & $4.4(1.6)$ & $4.7(1.3)$ & $5.1(1.2)$ & $4.6(1.4)$ & NS \\
\hline Having a sideline job $(\%)^{3}$ & 5.2 & 1.7 & 3.4 & 5.1 & 2.9 & 11.5 & $\mathrm{Chi}^{2}(5)=13.83, P=0.009$ \\
\hline \multicolumn{8}{|l|}{ Leisure activities } \\
\hline Going out, range $1-4$ (mean, SD) ${ }^{4}$ & $2.1(0.7)^{*}$ & $1.9(0.7)^{*}$ & $2.0(0.7)$ & $2.0(0.7)$ & $2.0(0.6)$ & $2.1(0.7)$ & $F(5)=3.16, P=0.004$ \\
\hline $\begin{array}{l}\text { Undertaking cultural activities, range } \\
1-4 \text { (mean, SD) }\end{array}$ & $1.7(0.5)$ & $1.7(0.5)$ & $1.7(0.5)$ & $1.7(0.5)$ & $1.8(0.5)$ & $1.7(0.5)$ & NS \\
\hline \multicolumn{8}{|l|}{ Friendship } \\
\hline Friendship, range $1-5$ (mean, SD) ${ }^{5}$ & $3.6(1.0)$ & $3.6(0.9)$ & $3.5(1.0)$ & $3.7(0.8)$ & $3.6(0.9)$ & $3.7(0.8)$ & NS \\
\hline
\end{tabular}

\section{REFERENCES}

1. Hassink EAM, Rieu PNMA, Brugman ATM, Festen C. Quality of life after operatively corrected high anorectal malformation: a long-term follow-up study in patients aged 18 years and older. $\mathrm{J}$ Pediatr Surg 1994; 29: 773-776.

2. Lubbers EJC. De ziekte van Crohn: sociale gevolgen. [Crohn's disease: social consequences.] Medisch Contact 1986; 43:1399-1402.

3. Drossman DA, Patrick DL, Mitchell CM, Zagami EA, Appelbaum MI. Health-related quality of life in inflammatory bowel disease. Dig Dis Sci 1989; 9:1379-1386.

4. Bekkers MJTM, van Knippenberg FCE, van Dulmen AM, van den Borne HW, van Berge Henegouwen GP. Survival and psychosocial adjustment to stomasurgery and nonstoma bowel resection: a 4 years follow-up. J Psychosom Res 1997; 3:235-244.

5. Sinnema G. De ontwikkeling van chronisch zieke adolescenten. [The development of chronically ill adolescents.] In: Bosch JD, Bosma HA, Oudshoorn DN, Rispens J, Vyt A, editors. Jaarboek Ontwikkelingspsychology: orthopedagogiek en kinderpsychiatrie. Houten/Diegem: Bohn Stafleu Van Lochum; 1996.

6. Sijbranda A, Visser M, Boonekamp G, Leurs M. Sport en bewegen voor chronische zieke jeugd. [Sport and exercise for youth with chronic conditions.] Arnhem: Stichting jeugd in beweging, NOC*NSF; 2000.

7. De Waal M, Donker G, van der Velden J. Spijsverteringsziekten onder de bevolking en in de huisartsenpraktijk. [Digestive disorders in general population and in general practice.] Utrecht: Nivel; 1992.

8. Van der Meer J, editor. Het Nederlandse leerboek voor interne geneeskunde. [Dutch textbook on internal medicine.] Bunnik: Bohn; 2000.

9. Krug E, Bergmeijer JH, Dees J, de Krijger R, Mooi WJ, Hazebroek FW. Gastroesophageal reflux and Barrett's esophagus in adults born with esophageal atresia. Am J Gastroenterol 1999; 10:2825-2828.

10. George EK, Mearin ML, Franken HCM, Houwen RH, Hirasing RA, Vandenbroucke JP. Twenty years of childhood coeliac disease in the Netherlands: a rapidly increasing incidence? Gut 1997; 40:61-66.

11. Bruijnzeel-Koomen C, Ortolani C, Bindslev-Jensen C, Björkstén B, Monoret-Vautrin D, Wútrich B. Adverse reaction to food. Position paper. Allergy 1995; 50:623-635.

12. World Health Organization. ICD-10: International statistical classification of diseases and related health problems. Geneva: World Health Organization; 1992.

13. Centraal Bureau voor de Statistiek (CBS). Statistical yearbook of the Netherlands. Voorburg/Heerlen: CBS; 1999.

14. Vogels T, van der Vliet R. Jeugd en seks. Gedrag en gezondheidsrisico's bij scholieren. [Youth and sex. Behaviour and health risks in pupils.] The Hague: SDU; 1990.

15. Centraal Bureau voor de Statistiek (CBS). Jeugd 1999. Cijfers en feiten. [Youth 1999. Figures and facts.] Voorburg/Heerlen: CBS; 1999. 
Calsbeek, H., Rijken, M., Bekkers, M.J.T.M., Kerssens, J.J., Dekker, J., Bergen Henegouwen, G.P. van Social position of adolescents with chronic digestive disorders.

European Journal of Gastroenterology \& Hepatology: 14, 2002, nr. 5, p. 543-549

16. Casellas F, López-Vivancos J, Badia X, Vilaseca J, Malagelada JR. Influence of inflammatory bowel disease on different dimensions of quality of life. Eur J Gastroenterol Hepatol 2001; 13:567572.

17. Swinkels MEM, van Weel C, Krabbe P, Rieu PNMA. Kwaliteit van leven na neonatale chirurgie. [Quality of life after neonatal surgery.] In: 25 Jaar kinderchirurgie in Nijmegen. Nijmegen: UMC St Radboud; 2000. pp. 77-80.

18. Henneman L, ten Kate LP, van der Ploeg HM, Bramsen I. CF in Nederland: resultaten van een landelijk onderzoek in 1997. [CF in the Netherlands: results of a national study in 1997.] Amsterdam: Vrije University; 1999. 